\title{
Spatial scales of snow texture as indicator for snow class
}

\author{
P.K. SATYAWALI, ${ }^{1}$ M. SCHNEEBELI ${ }^{2}$ \\ ${ }^{1}$ Snow and Avalanche Study Establishment, Manali, Himachal Pradesh 175 103, India \\ E-mail: pramodsatyawali@hotmail.com \\ ${ }^{2}$ WSL Institute for Snow and Avalanche Research SLF, Flüelastrasse 11, CH-7260 Davos Dorf, Switzerland
}

\begin{abstract}
A method for automated and fast classification of snow texture would be useful for applications where snow structure must be quantified. Large numbers of field measurements were carried out on natural snow in order to investigate small-scale variations of the micro-penetration force. Snow characterization was done for snow from the Himalaya and the Alps, using a high-resolution snow penetrometer (SnowMicroPen). Measurements of snow resistance at equal intervals of $4 \mu \mathrm{m}$ were geostatistically evaluated. The range parameter (correlation length, or $\mathrm{CL}$ ) of penetration force was estimated for all major snow classes from the sample semivariogram. Average CL was lowest for new snow and highest for melt-freeze snow. For major snow classes, CL was found to increase with snow density. Ground-perpendicular and ground-parallel snow profiles were also obtained for homogeneous snow, and CL was estimated along these directions. New snow showed larger $\mathrm{CL}$ in the ground-parallel direction, and depth-hoar snow showed larger $\mathrm{CL}$ in the ground-perpendicular direction. Based on $\mathrm{CL}$, the directional anisotropy was calculated. An attempt was also made to show the relationship between $\mathrm{CL}$ and texture index. The semivariogram was used to estimate the fractal dimension. Both $\mathrm{CL}$ and fractal dimension were found to be potential parameters to describe snow.
\end{abstract}

\section{INTRODUCTION}

The texture of snow is of critical importance to snow properties (Eugster, 1950; IASH Commission of Snow and Ice, 1954; Colbeck and others, 1990; Schneebeli and others, 1999). Increasingly, the more precise numerical simulation of snow (Brun and others, 1992; Lehning and others, 2002; Singh and others, 2004) is limited by the precision of observation. Almost all snow-pit measurements are subject to inaccuracy due to subjectivity associated with human perception. In the field, snow texture is recorded in terms of grain size and grain shape using visual techniques which can be highly subjective. In the cold laboratory, sections of snow samples are taken to obtain grain size and distinguish snow classes. The latter approach, while much more quantitative, is generally not chosen, due to time constraints and the difficulty of bringing field samples to the cold room. Due to its subjective nature, traditional classification shows a larger scatter of data. The consequence is an improper comparison of snow class between the datasets of different observers.

Schneebeli and others (1999) modelled texture index (TI) for snow from the data of a high-resolution snow penetrometer, the SnowMicroPen (SMP; J.B. Johnson and M. Schneebeli. 1998. Snow strength penetrometer. US Patent 5831161). The TI is defined as the ratio of the mean grain size to the volumetric density, which Schneebeli and others (1999) showed could be estimated from the coefficient of variance $(\mathrm{CV})$ of the SMP signal. They were able to partly correlate weak layers with the textural information as obtained from the penetration force data of SMP profiles (the full-length signal of snowpack). The CV is also used to quantify changes in texture (Pielmeier, 2003; Lutz and others, 2007). Pielmeier and others (2005) and Pielmeier and Schweizer (2007) compared SMP profile data with manual stability test scores and found them fairly reliable for predicting stability. Snow strength was also modelled using a micromechanical theory (Johnson and Schneebeli, 1999), but results were only qualitatively compared to descriptions of snow classes. Later, a statistically based micromechanical theory of cone penetration in granular material was developed by Johnson (2003), which takes into account the effects of cone geometry, material compaction and the dimension and strength of the microstructural elements that form the granular material. Johnson showed the dependence of cone penetration resistance on cone half-angle and concluded that the micromechanical theory may provide a means to directly determine geotechnical properties of granular materials. Satyawali and others (2009) characterized Alpine snow based on a hierarchical look-up table supported by a database of classified SMP profiles. The approach was found to be useful for detecting snow class with reasonable accuracy. Matzl and Schneebeli (2006) used infrared photography to estimate optical equivalent snow grain size directly from the snow pit. Dadic and others (2008) used SMP profile data to capture more detailed information on snowpack, and found that high-resolution data were necessary to accurately model near-surface temperatures in polar snow.

None of these methods provides satisfactory results for snow characterization in an objective manner. The current method of snow characterization using SMP measurements is based on simple moments, so a new method is developed in the present work to improve snow classification using geostatistics. The method is based on the spatial measures of snow estimated from the semivariogram (SV). It is recognized that combining simple moments and spatial measures will improve snow classification.

Several recent studies on snow, which are based on the application of geostatistics (Webster and Oliver, 2001), estimate the SV (Pielmeier, 2003; Birkeland and others, 2004; Kronholm, 2004; Kronholm and others, 2004; Lutz and others, 2007) for quantifying the spatial variability of selected snow layers. Lutz and others (2007) found a microscale correlation length of $80 \mu \mathrm{m}$ within a weak layer. Using a micromechanical model (Johnson and Schneebeli, 

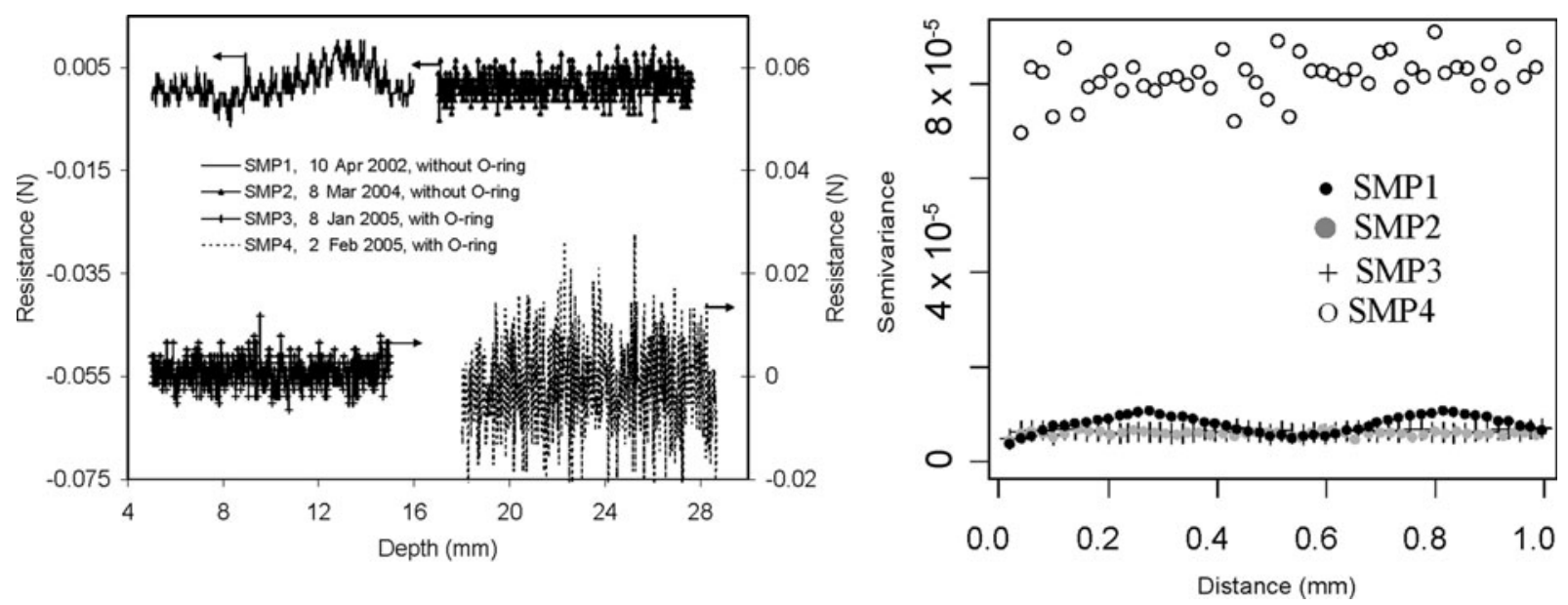

Fig. 1. Comparison of air signal for different SMPs used in the present work (a) with semivariance analysis (b).

1999; Johnson, 2003), Lutz (2009) estimated micromechanical parameters of weak interfaces from the SMP data and found variability over time and space. Using compression test results and the autocorrelation function on SMP penetration resistance, Van Herwijnen and others (in press) were able to resolve layer boundaries and the failure layers. Estimating the correlation length for an entire snow class could be useful for future research on snow classification.

Natural phenomena such as earthquake distribution, biological systems, geological structures and geophysical properties are mainly described as self-affine fractals by many researchers (Korvin, 1992; De Santis and others, 1997; Turcotte, 1997; Dimri, 2000; Bansal and Dimri, 2005; Chamoli, and others, 2007). Carr (1995) used the SV to estimate the fractal dimension (FD) of a stochastic fractal. Mela and Louie (2001) used the SV to obtain the correlation length and FD of seismic data. In general, as measurement scale becomes smaller the corresponding measured property shows fractal behaviour (Feder, 1988; Cross, 1997; Wallace and others, 2004). In snow, since ice and pores are randomly distributed even for a homogeneous snow, the high-resolution SMP data of snow resistance exhibit it in the form of varying penetration force. Deems and others (2006) observed the spatial distribution of snow depth at horizontal scales from 1 to $1000 \mathrm{~m}$ using variogram fractal analysis and found two distinct FDs for short- and long-range correlation.

In the present work, we show the range parameter (hereafter correlation length $(\mathrm{CL})$ ) of major snow classes as estimated from the SV. SMP measurements were also taken in the ground-parallel direction in the snowpack while supported on the level ground. CL was obtained along this direction, and a ratio of $\mathrm{CL}$ in the ground-parallel and ground-perpendicular direction is used to estimate directional anisotropy. An attempt was also made to show the relation between $\mathrm{TI}$ and $\mathrm{CL}$. The SV method is also used to estimate the FD of the penetration force data from the loglog plot of the SV (e.g. Zhang and others, 2005), and the dependence of the FD on snow class is demonstrated.

\section{METHODS}

\subsection{Experimental site and data collection}

In order to estimate the spatial scales for different snow classes from the field, precise measurement of the snow layers (in SMP profile and hand profile) is very important.
The present study is based on measurements made for snow at Patsio, Himachal Pradesh, India $\left(32.75^{\circ} \mathrm{N}, 77.25^{\circ} \mathrm{E}\right.$; $3800 \mathrm{~m}$ a.s.l.), and at Davos, Switzerland $\left(46.48^{\circ} \mathrm{N}, 9.49^{\circ} \mathrm{E}\right.$; 1560 ma.s.l.). The SMP profiles and manual snow-pit measurements were taken during mid-winter to late winter in order to ensure that major snow classes were captured. These measurements were done for ground-parallel and ground-perpendicular directions along with manual snowpit profiles. The details of each SMP profile, with date, snow class, snow density and profile direction, are given in Table 1. Measurements were made on 7 days ( 5 days at Patsio during 2001/02 and 2003/04, and 2 days at Davos during 2004/05), resulting in a total of 98 SMP profiles from Patsio and 58 SMP profiles from Davos (Table 1, column 2) available for analysis.

The SMP records penetration force data at $4 \mu \mathrm{m}$ intervals. Such closely spaced data allowed geostatistics to be applied even for a SMP profile segment of $<20 \mathrm{~mm}$. In the present work, a $20 \mathrm{~mm}$ SMP profile segment was selected for analysis of all the snow classes. Precise matching of SMP profile segments with the snow-pit profile is very important. A $20 \mathrm{~mm}$ profile segment for a particular snow class was selected visually by matching the snow-pit profile with the SMP profile. Thin snow layers were not considered, as they could be visually missed in the SMP profile. Only thick prominent snow layers from both the profiles (SMP and manual) were considered for this analysis. In this way, manual error in aligning the SMP and the snow-pit profiles was minimized.

\subsection{Performance of different SMPs}

In the present study, four different SMPs were used to take the snow profile. The semivariance of the air signal was analysed for all the SMPs as in Lutz (2009). The air signal was recorded before the sensor tip entered the snowpack. It was taken from a $10 \mathrm{~mm}$ segment and plotted for $0.02 \mathrm{~mm}$ lag distance for all the SMPs (Fig. 1). The semivariance shows no spatial correlation, but a pure nugget effect. For three of the SMPs (SMP1, SMP2, SMP3) the semivariance was found to be around $10^{-6} \mathrm{~N}^{2}$, and for one (SMP4) about $10^{-5} \mathrm{~N}^{2}$. SMP4 had different, coarser, gear spacing than the other SMPs. However, the variance is very small compared to the typical penetration resistance of the snow investigated here. In this study, the data were not examined for poor-quality signal. In addition, we did not use a micromechanical model (Johnson 
Table 1. Mean spatial data obtained for various snow classes over $20 \mathrm{~mm}$ distance. The snow class codes are according to Colbeck and others (1990). SD: standard deviation; V: ground-perpendicular, H: ground-parallel, NR: not recorded; P: Patsio; D: Davos

\begin{tabular}{|c|c|c|c|c|c|c|c|c|c|c|c|c|c|c|c|}
\hline \multirow[t]{2}{*}{ No } & \multirow[t]{2}{*}{$\begin{array}{l}\text { Profile name } \\
\text { and date }\end{array}$} & \multirow[t]{2}{*}{$\begin{array}{l}\text { Number } \\
\text { of profiles }\end{array}$} & \multirow[t]{2}{*}{$\begin{array}{l}\text { Snow } \\
\text { class } \\
\text { code }\end{array}$} & \multirow{2}{*}{$\begin{array}{l}\text { MPF } \\
\text { N }\end{array}$} & \multirow{2}{*}{$\begin{array}{c}\mathrm{SD}, \mathrm{MPF} \\
\mathrm{N}\end{array}$} & \multirow{2}{*}{$\begin{array}{c}\text { Sill } \\
\text { variance } \\
\mathrm{N}^{2}\end{array}$} & \multirow{2}{*}{$\begin{array}{c}\mathrm{SD} \text {, sill } \\
\text { variance } \\
\mathrm{N}^{2}\end{array}$} & \multirow{2}{*}{$\begin{array}{l}\mathrm{CL} \\
\mathrm{mm}\end{array}$} & \multirow{2}{*}{$\begin{array}{l}\mathrm{SD}, \mathrm{CL} \\
\mathrm{mm}\end{array}$} & \multirow[t]{2}{*}{ FD } & \multirow[t]{2}{*}{$\mathrm{SD}, \mathrm{FD}$} & \multirow[t]{2}{*}{$\begin{array}{c}\text { Profile } \\
\text { direction }\end{array}$} & \multirow{2}{*}{$\begin{array}{l}\text { Grain } \\
\text { size } \\
\text { mm }\end{array}$} & \multirow{2}{*}{$\begin{array}{l}\text { Snow } \\
\text { density } \\
\mathrm{kg} \mathrm{m}^{-3}\end{array}$} & \multirow[t]{2}{*}{$\begin{array}{c}\text { Station } \\
\text { code }\end{array}$} \\
\hline & & & & & & & & & & & & & & & \\
\hline 1 & Pat8, 8 Mar 2004 & 9 & $4 a, b$ & 0.166 & 0.0138 & 0.020 & 0.004 & 0.098 & 0.025 & 1.80 & 0.11 & V & $1-2.0$ & 280 & $P$ \\
\hline 2 & Pat10, 8 Mar 2004 & 10 & $4 a, b$ & 0.241 & 0.0276 & 0.026 & 0.009 & 0.073 & 0.013 & 1.89 & 0.07 & $\mathrm{H}$ & $1-2.0$ & 280 & $P$ \\
\hline 3 & Pato7, 3 Apr 2002 & 7 & $4 a, b$ & 0.220 & 0.0074 & 0.002 & 0.001 & 0.211 & 0.082 & 1.75 & 0.12 & $\mathrm{~V}$ & $1.5-2.5$ & NR & $P$ \\
\hline 4 & Obs7, 8 Apr 2002 & 12 & $4 a, b$ & 0.223 & 0.0473 & 0.005 & 0.001 & 0.104 & 0.019 & 1.80 & 0.05 & V & $1.5-2.5$ & NR & $P$ \\
\hline 5 & Vert23, 2 Feb 2005 & 7 & $4 a, b$ & 0.039 & 0.0055 & 0.034 & 0.009 & 0.04 & 0.006 & 1.92 & 0.03 & V & $1-2.0$ & 209 & $\mathrm{D}$ \\
\hline 6 & Vert10, 2 Feb 2005 & 7 & $4 a, b$ & 0.048 & 0.0064 & 0.035 & 0.004 & 0.039 & 0.003 & 1.91 & 0.04 & $\mathrm{H}$ & $1-2.0$ & 209 & $\mathrm{D}$ \\
\hline 7 & Pat8, 8 Mar 2004 & 3 & $5 a$ & 0.624 & 0.1572 & 0.077 & 0.014 & 0.304 & 0.044 & 1.68 & 0.1 & V & $2.5-3.5$ & 320 & $P$ \\
\hline 8 & Pat9, 8 Mar 2004 & 26 & $5 \mathrm{a}$ & 0.381 & 0.0376 & 0.028 & 0.006 & 0.155 & .034 & 1.76 & $0 .($ & $\mathrm{H}$ & $2.5-3.5$ & 320 & $P$ \\
\hline 9 & Pato7, 3 Apr 2002 & 6 & $5 a$ & 0.259 & 0.033 & 0.018 & 0.005 & 0.374 & 0.066 & 1.6 & 0.0 & V & $3-4.0$ & NR & $\mathrm{P}$ \\
\hline 10 & Zing1, 5 Apr 2002 & 2 & $5 a$ & 0.248 & 0.0117 & 0.007 & 0.002 & 0.193 & 0.021 & 1.76 & 0.04 & V & $2.5-4.0$ & $N R$ & $P$ \\
\hline 11 & Obs7, 8 Apr 2002 & 5 & $5 a$ & 0.467 & 0.064 & 0.028 & 0.013 & 0.353 & 0.115 & 1.56 & 0.08 & V & $3.5-4.5$ & $N R$ & $P$ \\
\hline 12 & Vert28, 2 Feb 2005 & 9 & $5 a$ & 0.076 & 0.02 & 0.068 & 0.017 & 0.137 & 0.034 & 1.73 & 0.06 & V & $1-4.0$ & 230 & $\mathrm{D}$ \\
\hline 13 & Vert14, 2 Feb 2005 & 6 & $5 a$ & 0.077 & 0.0154 & 0.072 & 0.013 & 0.103 & 0.023 & 1.78 & 0.07 & $\mathrm{H}$ & $1-4.0$ & 230 & $\mathrm{D}$ \\
\hline 14 & Pat8, 8 Mar 2004 & 2 & $3 a, b$ & 0.686 & 0.6459 & 0.009 & 0.005 & 0.063 & 0.001 & 1.92 & 0.08 & V & $0.25-0.5$ & 320 & $P$ \\
\hline 15 & Pat11, 8 Mar 2004 & 8 & $3 a, b$ & 1.161 & 0.0469 & 0.006 & 0.001 & 0.103 & 0.05 & 1.89 & 0.06 & $\mathrm{H}$ & $0.25-0.5$ & 320 & $P$ \\
\hline 16 & Sty20, 8 Jan 2005 & 6 & $3 a, b$ & 0.036 & 0.0021 & 0.025 & 0.006 & 0.054 & 0.014 & 1.88 & 0.07 & V & $0.75-1$ & 186 & $\mathrm{D}$ \\
\hline 17 & Sty22, 8 Jan 2005 & 5 & $3 a, b$ & 0.044 & 0.0011 & 0.015 & 0.001 & 0.042 & 0.012 & 1.95 & 0.03 & $\mathrm{H}$ & $0.75-1$ & 186 & $\mathrm{D}$ \\
\hline 18 & Sty15, 8 Jan 2005 & 2 & $\begin{array}{c}1 \mathrm{~d}, 1 \mathrm{e} \\
2 \mathrm{a}\end{array}$ & 0.011 & 0.0002 & 0.023 & 0.001 & 0.017 & 0.0 & 1.97 & 0.04 & V & $0.25-0.5$ & 155 & $\mathrm{D}$ \\
\hline 19 & Sty12, 8 Jan 2005 & 2 & $\begin{array}{c}1 \mathrm{~d}, 1 \mathrm{e} \\
2 \mathrm{a}\end{array}$ & 0.015 & 0.0003 & 0.017 & 0.002 & 0.027 & 0.004 & 1.88 & 0.02 & $\mathrm{H}$ & $0.25-0.5$ & 155 & $\mathrm{D}$ \\
\hline 20 & Vert19, 2 Feb 2005 & 5 & $3 a, b$ & 0.105 & 0.0234 & 0.022 & 0.032 & 0.018 & 0.006 & 1.88 & 0.04 & V & $0.5-0.75$ & 172 & $\mathrm{D}$ \\
\hline 21 & Vert4, 2 Feb 2005 & 9 & $3 a, b$ & 0.216 & 0.0436 & 0.006 & 0.001 & 0.037 & 0.012 & 1.91 & 0.04 & $\mathrm{H}$ & $0.5-0.75$ & 172 & $\mathrm{D}$ \\
\hline 22 & Tila3, 10 Apr 2002 & 8 & $6 b$ & 2.202 & 0.5622 & 0.083 & 0.028 & 0.544 & 0.209 & 1.52 & 0.08 & V & NR & $N R$ & $P$ \\
\hline
\end{tabular}

and Schneebeli, 1999) which can be sensitive to instrument noise (Lutz, 2009).

\subsection{Estimation of semivariogram}

The SV relates the variance in values of an attribute at pairs of sample points to separation distance between the points of a given pair. It is therefore a measure of spatial dependence of a variable over some distance. The SV can be used to determine the scaling properties of self-affine series (Oliver and Webster, 1986), which are related to lag distance $(h)$ as follows (Cressie, 1993):

$$
\gamma(h)=\frac{1}{2(N-h)} \sum_{i=1}^{(N-h)}\left\{\left[Y\left(x_{i}\right)-Y\left(x_{i+h}\right)\right]^{2}\right\} .
$$

$\gamma(h)$ is defined as the experimental SV or sample SV, i.e. one based on the sampled dataset, $(N-h)$ is the number of pairs at lag distance $h$, and $Y\left(x_{i}\right)$ is the parameter value at position i. $\gamma(h)$ is then plotted against the lag distance between the initial point and the compared points. The plot typically results in a curve where SV value increases with distance to a maximum, and then levels off if the distance between measurement points exceeds the distance at which spatial structure exists. A continuous process without spatial dependence will result in a horizontal line beyond the $C L$, called sill variance. The lag distance where the model SV reaches the sill variance is called $\mathrm{CL}$. The $\mathrm{CL}$ is the maximum distance over which there is spatial autocorrelation. The nugget variance is caused mainly by variance over distances less than the sampling interval and also due to measurement error.
For calculation of $\mathrm{CL}$, the SVs were plotted only up to one-quarter of the extent of data because the SV is not reliable for the lag distance beyond this limit (Oliver and Webster, 1986). According to Pfeiffer (1996), 'Estimates of the SV are considered to be more robust to departures from stationarity represented as a general trend in the spatial process'. Jaksa and others (1993) showed that sampling at close spacing is very important in estimating SV, as the larger-spaced sample data reach the sill variance at the very beginning. It is therefore visualized that SMP data can be used in estimating SV, as they capture high-resolution information at equally spaced intervals.

\subsection{Processing of SMP profile data}

For each snow class, a fixed segment $20 \mathrm{~mm}$ long is selected from the SMP profile for the purpose of estimating the SV. It was first ascertained that SMP data belong to a log-normal distribution. This was done by applying a log transformation to the SMP profile segment. The distribution was checked by a quantile-quantile (QQ) plot, which shows a straight line for normally distributed data.

Similar to the autocorrelation function of random variables, the SV requires stationary data, which means that it should depend only on the separation distance and not on the locality of the pairs. As a result, if a drift or trend exists in the data, it must first be removed. Davis (1986) showed that if the trend is subtracted from the variables, the residuals themselves will be a variable with a local mean value of zero. An example of a typical trended penetration-force record for a rounded-grain snow layer is shown in Figure 2a. The QQ plot (Fig. 2b) shows that these data are far from the 

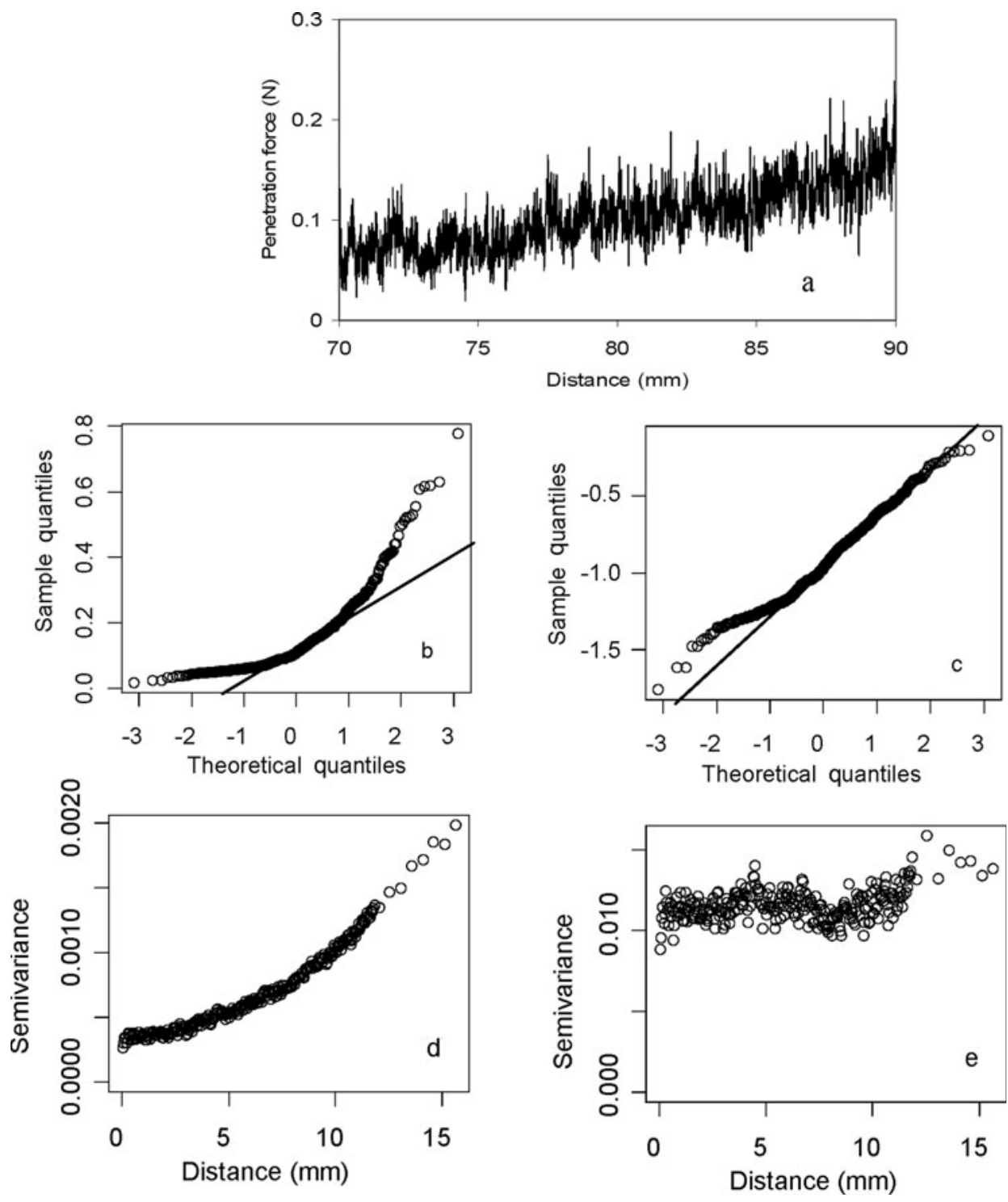

Fig. 2. (a) Signal from a segment of $20 \mathrm{~mm}$ SMP profile of rounded-grain snow. (b) QQ plot of sample data. (c) QQ plot after log transformation. (d) SV of trended data. (e) SV of detrended data.

normal distribution and require treatment to make them normal before estimating the SV. Figure 2c shows the QQ plot after a log transformation is applied. The SV (Fig. 2d and e) is shown before and after the linear trend is removed from the data using statistical software ' $R$ ' (Ribeiro and Diggle, 2001).

A total of 156 samples of the SV were studied for all the snow classes. The fitting of the SV was done by the ordinary least-squares method (Cressie, 1993, p. 94) implemented in the $\mathrm{R}$ function 'VARIOFIT'. At large lag distances, the number of point pairs in each lag distance becomes relatively small. This method ensures that outliers in the data are handled automatically by giving them low weight (this was done by taking more than 200 data pairs for each lag distance) in the calculation of the SV. The sample SV is modelled with an exponential SV model plus a zero nugget (Equation (2)) as:

$$
\gamma(h)=c\left(1-\mathrm{e}^{-\frac{h}{a}}\right)+c_{0}
$$

where $c+c_{0}$ is sill variance, $a$ is $C L$ and $c_{0}$ is nugget. These parameters are used to describe the SV.

\subsection{Estimation of correlation length and texture index}

To estimate CL for a full-depth SMP profile, the SV was first obtained for a $5 \mathrm{~mm}$ profile length, starting from top to bottom continuously. Since there were chances to capture more than two homogeneous snow layers for a $20 \mathrm{~mm}$ profile length, SV was only estimated for a $5 \mathrm{~mm}$ profile length to reduce error. Estimates of the SV for segments less than $5 \mathrm{~mm}$ were not considered because of the cone tip size of the SMP, which is $4.3 \mathrm{~mm}$ (Lutz and others, 2007). The CL was than compared with the $\mathrm{TI}$ and plotted against snow depth as shown later.

\subsection{Estimation of fractal dimension}

The following relationship is used to obtain FD by utilizing the slope of a log-log plot of the SV (Carr, 1995):

$$
\mathrm{FD}=2-\frac{S}{2}
$$

where $S$ is the slope of the straight line fitted to the linear portion of a log-log plot of the SV. The linear portion was chosen for the data up to the CL distance. 

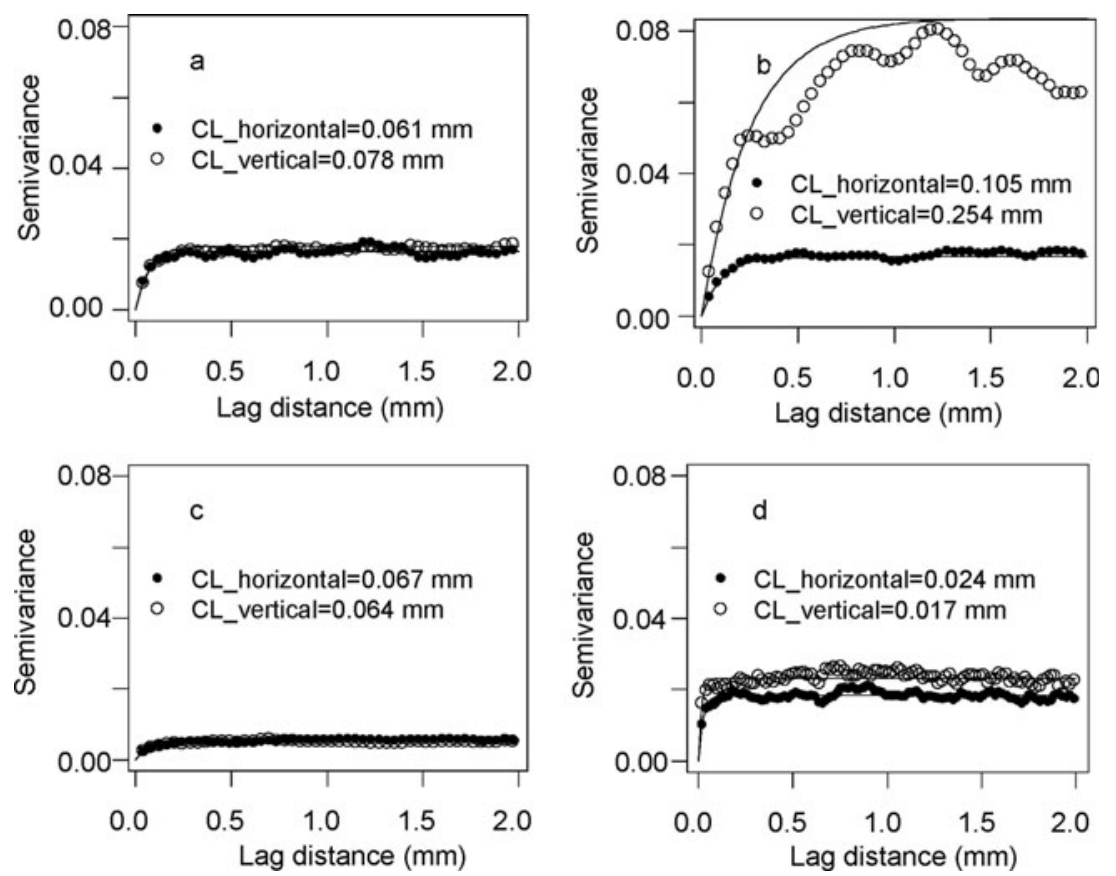

Fig. 3. Sample and modelled (exponential) SV for (a) faceted snow, (b) depth hoar, (c) rounded grain and (d) new snow. (Prefix $\mathrm{CL}_{-}$is correlation length.)

\section{RESULTS AND DISCUSSION}

After analyzing the $\mathrm{SV}$, it was found that $\mathrm{CL}$, sill variance and nugget from the fitted models for each class varied slightly. For most cases, the exponential model (Equation (2)) provided the best visual fit. To ensure that the parameters of the model SV were directly comparable, the best-fit model (exponential) was used for the analyses. This seems a reasonable choice because the results of kriging are much the same for any reasonable choice of SV model (Webster and Oliver, 2001). The results of the statistical analysis are given in Table 1 which shows the mean penetration force (MPF) averaged over $1 \mathrm{~mm}$ profile length, sill variance, $\mathrm{CL}$ and FD with their standard deviations. Snow density and grain size as measured during pit profiles are also given. Himalayan snow had higher average density $\left(307 \pm 20 \mathrm{~kg} \mathrm{~m}^{-3}\right)$ than Alpine snow $\left(190 \pm 28 \mathrm{~kg} \mathrm{~m}^{-3}\right)$.

\subsection{Sill variance}

Rounded-grain snow showed higher sill variance in the ground-perpendicular direction, and faceted-grain snow in the ground-parallel direction (see Table 1). The sill variance of depth-hoar snow (profile Nos. 7 and 8) for Himalayan snow is higher than for Alpine snow (profile Nos. 12 and 13), but a significant difference was not observed.

Figure 3a-d show the sample SV obtained for faceted snow, depth hoar, rounded-grain snow and new snow respectively. The model SV (exponential) is also plotted for all the snow classes. Sill variance is highest for depth hoar and lowest for rounded-grain snow. Cyclic behaviour of the SV was also noticed for depth-hoar snow at small distances.

\subsection{Mean penetration force, correlation length and anisotropy}

The MPF for all the measured snow classes was analysed. As expected, it was found to be highest for melt-freeze snow and lowest for new snow (Table 1). Depth-hoar and facetedgrain snow show low MPF values, with faceted-grain snow showing the lower values. Rounded-grain snow shows intermediate MPF values, with large scatter due to varying snow density and bonding (not measured in the present work). From Table 1 (profile Nos. 14-21), most of the layer analysis for rounded-grain snow suggests that snow resistance is greater in the ground-parallel than in the groundperpendicular direction.

As the SV was estimated in both directions, the ratio of the directional $\mathrm{CL}$ (also defined as anisotropy) is further utilized in the interpretation of the data. Figure $3 a-d$ show the SV obtained for different snow classes in different directions. Shortly after it is deposited, as snow is relatively new or slightly metamorphosed, the $\mathrm{CL}$ is greater in the ground-parallel direction (Fig. 3d). For new snow, the ratio of the CL (ground-parallel to ground-perpendicular direction) as averaged for the present data is 1.59 (Table 1). It is logical that new snow crystals tend to descend with the basal plane parallel to the horizontal plane. Once snow is settled, the metamorphic process alters the grain shape into a rounded or angular shape depending on temperatures and temperature gradients. This results in varying $C L$ values for different snow classes. The anisotropy therefore changes with the metamorphic processes. For rounded-grain snow, the ratio was 1.63 , and for faceted-grain snow it was 0.74 , i.e. less than 1 . This means that snow textures dominate in the ground-perpendicular direction for this snow. For welldeveloped depth-hoar snow, the ratio was found to be even less (0.51). This implies that more alignment of snow texture takes place in the ground-perpendicular direction as snow changes shape from new snow to depth hoar. This analysis gives an idea how snow texture develops with time as snow metamorphism progresses. However, it is worth mentioning that, due to the tip geometry of the SMP, it is not known whether the dimensions are physically related only to the snow structure, or to the size and geometry of the tip as well.

Figures 4 and 5 show the MPF and CL respectively. Boxes show the interquartile range from the first to third quartile, with a horizontal line showing the median. Himalayan snow 


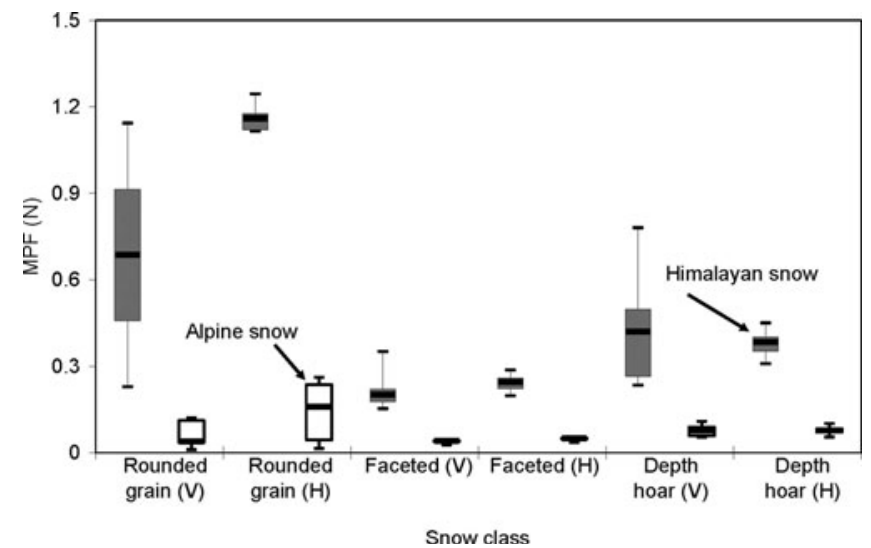

Fig. 4. Box plot of mean penetration force (MPF). Himalayan snow is shown in shaded gray and alpine snow shown with white box plots. The data are from a sample size of 156 as shown in Table 1. Snow profiling in the ground-parallel and ground-perpendicular directions is represented by $\mathrm{H}$ and $\mathrm{V}$ respectively.

(grey boxes) shows higher values of MPF and CL. MPF is found more in the ground-parallel direction $(\mathrm{H})$ than the ground-perpendicular direction (V) for both Himalayan and Alpine snow (white boxes), except for Himalayan depth hoar. Among all snow classes, Himalayan rounded-grain snow shows higher MPF in the ground-parallel direction. The $C L$ is higher in the ground-perpendicular direction than the ground-parallel direction for the same class of snow. Depth hoar shows the highest value of $\mathrm{CL}$ in the groundperpendicular direction.

\subsection{Comparison of correlation length with texture index}

The CL for a full-depth SMP profile for Himalayan snow (using SMP2) and for Alpine snow (using SMP4) is plotted along with the penetration force and TI (Figs 6 and 7). Details of the hand profile are given in Tables 2 and 3 respectively. The $C L$ in both profiles provides a satisfactory comparison with the $\mathrm{TI}$, at least visually, showing the potential of this approach. Because the TI correlates well to the grain size (Schneebeli and others, 1999), CL must also be correlated to grain size. The correlation is not obtained between $\mathrm{CL}$ and $\mathrm{TI}$, as these parameters are estimated for varying profile length.

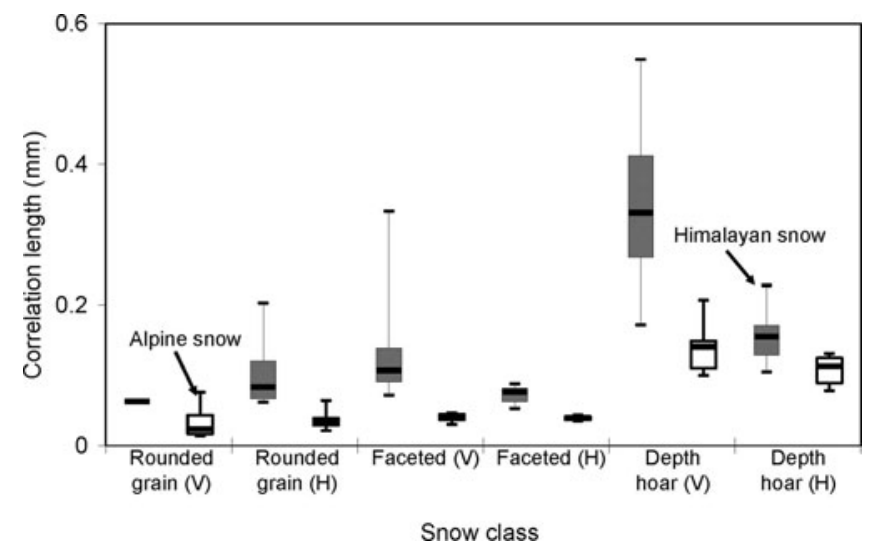

Fig. 5. Box plot of correlation length $(\mathrm{CL})$. Himalayan snow is shown in shaded gray and alpine snow shown with white box plots. The data are from a sample size of 156 as shown in Table 1. H and $\mathrm{V}$ represent terms similar to those in Figure 4.

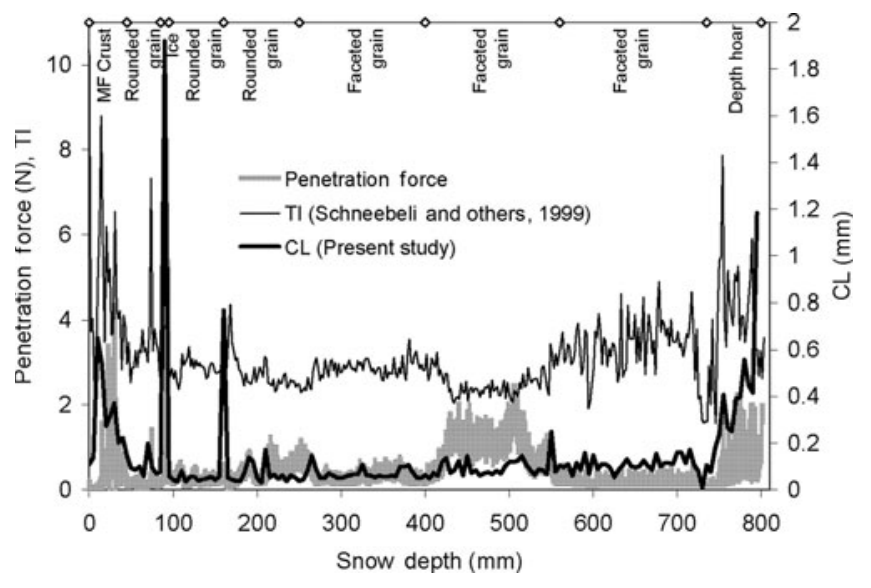

Fig. 6. Comparison of penetration force and texture index (TI) with CL for Himalayan snowpack. Observed snow class is also shown. Details of hand profile given (Table 2$).(\diamond$ : layer interface marker.)

\subsection{Fractal dimension}

The FD can be estimated from the SV (Carr, 1995) provided the data are sampled at equal intervals to indicate the similarity of the features under study. The evenly spaced data of the SMP are therefore well suited to such analysis. Figure 8 shows an example of the SV plotted on a log-log scale for four major snow classes. A linear regression was obtained for all the data below the CL distance, which shows a linear portion on a log-log scale. Once the slope is estimated, the FD is calculated using Equation (3). FDs in the ground-parallel and ground-perpendicular directions show no definite correlation (Table 1; Fig. 9). The average FD for Himalayan and Alpine snow, however, varies according to snow class, being highest for rounded-grain snow and lowest for melt-freeze snow ( $F D_{\text {Rounded_grain }}=1.91 \pm 0.035$, $\mathrm{FD}_{\text {Faceted_grain }}=1.85 \pm 0.07, \quad \mathrm{FD}_{\text {Depth_hoar }}=1.7 \pm 0.09$ and $\mathrm{FD}_{\text {Melt-freeze }}=1.52 \pm 0.08$ )

The directional distribution of the FD for Himalayan and Alpine snow is shown in Figure 9. Himalayan snow shows lower FD values than Alpine snow for all the snow classes. Depth-hoar snow shows the smallest values of FD in the ground-perpendicular direction for both Himalayan and Alpine snow.

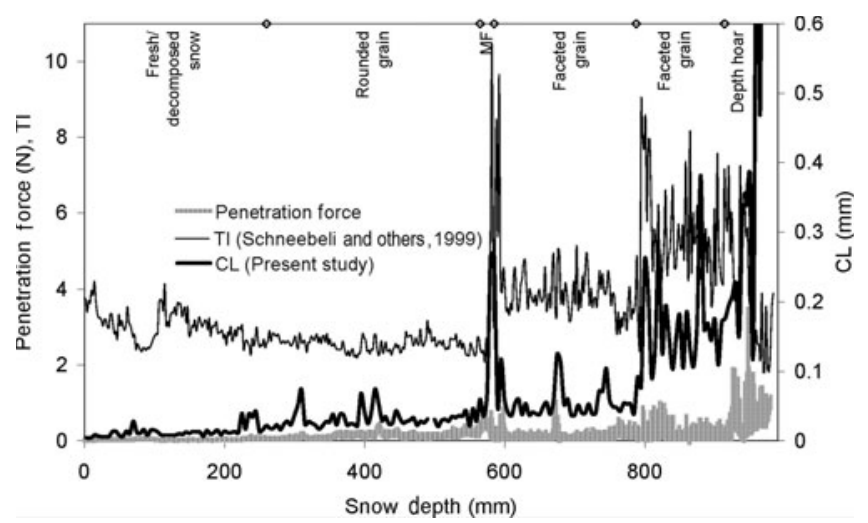

Fig. 7. Comparison of penetration force and TI with CL for Alpine snowpack Observed snow class is also shown. Details of hand profile given (Table 3$)$. ( $\diamond$ : layer interface marker.) 
Table 2. Details of hand profile for Himalayan snowpack taken on 8 March 2004. The snow class codes are according to Colbeck and others (1990). NR: not recorded

\begin{tabular}{lccccc}
\hline $\begin{array}{l}\text { Snow } \\
\text { layer }\end{array}$ & $\begin{array}{c}\text { Snow layer } \\
\text { depth }\end{array}$ & Grain size & $\begin{array}{c}\text { Av. layer } \\
\text { temp. }\end{array}$ & Snow class & Density \\
& $\mathrm{cm}$ & $\mathrm{mm}$ & ${ }^{\circ} \mathrm{C}$ & & $\mathrm{kg} \mathrm{m}^{-3}$ \\
\hline Surface & 0 & & -13.0 & & \\
1 & $0-5$ & $3-4$ & -12.0 & $6 \mathrm{~b}$ & 376 \\
2 & $5-14$ & $0.5-1.0$ & -10.0 & $3 \mathrm{a}, \mathrm{b}$ & 282 \\
3 & $14-15$ & - & $\mathrm{NR}$ & Ice layer & $\mathrm{NR}$ \\
4 & $15-19$ & $0.5-1.0$ & -8.0 & $3 \mathrm{a}, \mathrm{b}$ & 323 \\
5 & $19-27$ & $1.0-1.5$ & -6.5 & $3 \mathrm{a}, \mathrm{b}$ & 320 \\
6 & $27-41$ & $0.5-1.5$ & -6.5 & $4 \mathrm{a}, \mathrm{b}$ & 298 \\
7 & $41-55$ & $1.0-1.5$ & -6.5 & $4 \mathrm{a}, \mathrm{b}$ & 373 \\
8 & $55-63$ & $1.0-2.0$ & -6.5 & $4 \mathrm{a}, \mathrm{b}$ & 276 \\
9 & $63-89$ & $3.0-4.0$ & -4.5 & $5 \mathrm{a}$ & 316 \\
\hline
\end{tabular}

The variation of $\mathrm{CL}$ with $\mathrm{FD}$ is shown in Figure 10 along with uncertainty in the measurement. It shows a better grouping of data, as different datasets lie in a particular range. In each case, $\mathrm{CL}$ is found to decrease with increasing FD values. Small FD values correspond to coarser grains, and larger values to finer particles.

\section{CONCLUSION}

One-dimensional semivariance analysis helped in the description and modelling of snow characterization from penetration force data of SMP profiles obtained through a high-resolution penetrometer (J.B. Johnson and M. Schneebeli, US Patent 5831161). The SV is plotted to estimate the spatial scales of various snow classes. The range parameter
Table 3. Details of hand profile for Alpine snowpack taken on 2 February 2005. The snow class codes are according to Colbeck and others (1990). NR: not recorded

\begin{tabular}{lccccc}
$\begin{array}{c}\text { Snow layer Snow layer } \\
\text { depth } \\
\mathrm{cm}\end{array}$ & $\begin{array}{c}\mathrm{mm} \\
\mathrm{mm}\end{array}$ & $\begin{array}{c}{ }^{\circ} \mathrm{C} \\
\text { temp. }\end{array}$ & & $\mathrm{kg} \mathrm{m}^{-3}$ \\
\hline Surface & 0 & & $\mathrm{NR}$ & & \\
1 & $0-26$ & $0.25-0.75$ & -8.0 & $1 \mathrm{~d}, 2 \mathrm{a}$ & 77 \\
2 & $26-63$ & $0.5-0.75$ & -7.8 & $3 \mathrm{a}, \mathrm{b}$ & 172 \\
3 & $63-65$ & $2.0-4.0$ & $\mathrm{NR}$ & $6 \mathrm{~b}$ & $\mathrm{NR}$ \\
4 & $65-73$ & $1.0-2.0$ & -4.5 & $4 \mathrm{a}, \mathrm{b}$ & 209 \\
5 & $73-81$ & $1.0-2.0$ & -3.5 & $4 \mathrm{a}, \mathrm{b}$ & 220 \\
6 & $81-100$ & $1.0-4.0$ & -1.3 & $5 \mathrm{a}$ & $\mathrm{NR}$
\end{tabular}

obtained from the SV is interpreted as the CL. The SV extracted from the SMP profiles is found to be useful for interpreting spatial scales. For all snow classes, $C L$ is generally found to increase with snow density. However, to validate this fact, sufficient data covering a wider range (over both time and space) will be required. This was beyond the scope of the present work. The Patsio and Davos sites were considered to show the potential of this method for acceptable characterization of identical snow even from different locations.

Directional SV obtained for major snow classes can be used to interpret the snow property. The spatial length shifts from a maximum in the ground-parallel to ground-perpendicular direction with an increasing degree of temperature gradient metamorphism. The study, however, lacks the data of average temperature gradient and temperature for validation. The FD of penetration force was obtained from the log-log plot of the SV, and was found to be useful for characterization of snow.
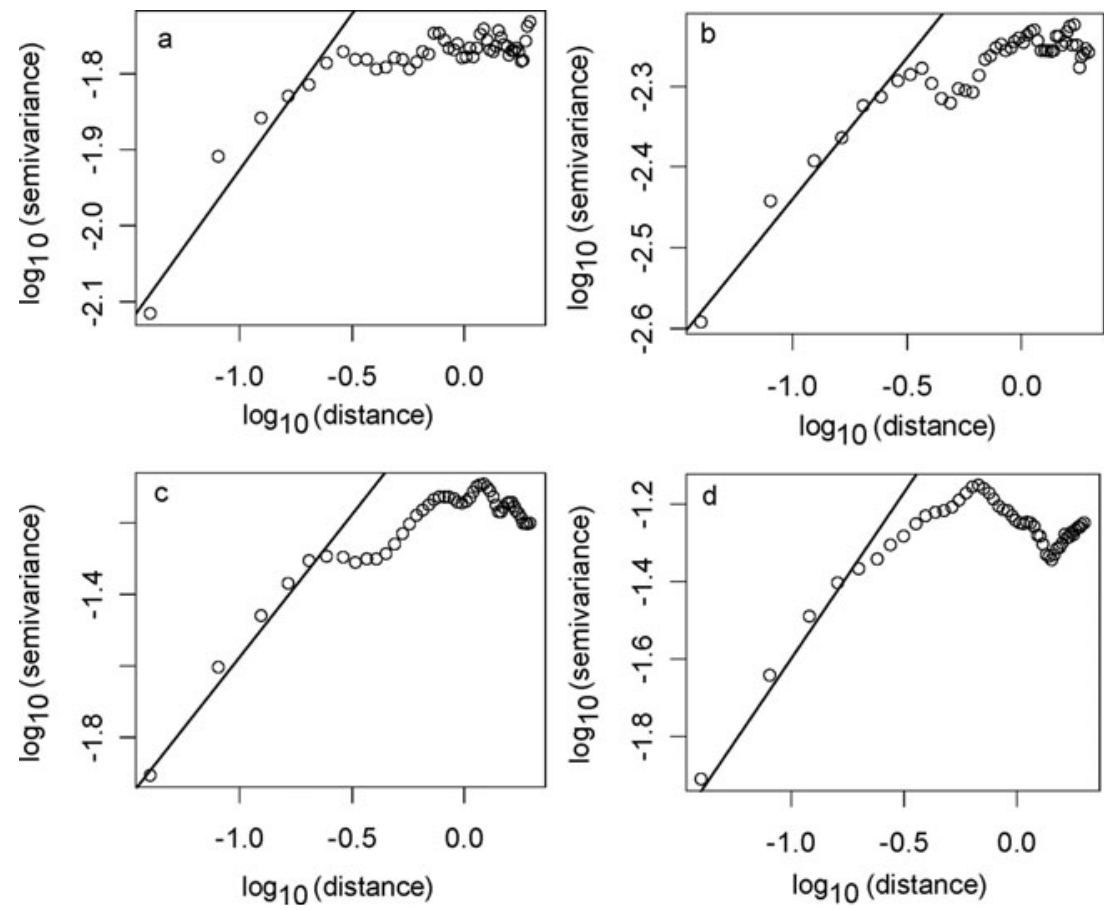

Fig. 8. Log-log plots of SV: (a) faceted snow, (b) rounded-grain snow, (c) depth hoar and (d) melt-freeze. A linear regression line (considering first six points) is drawn to find the slope. 


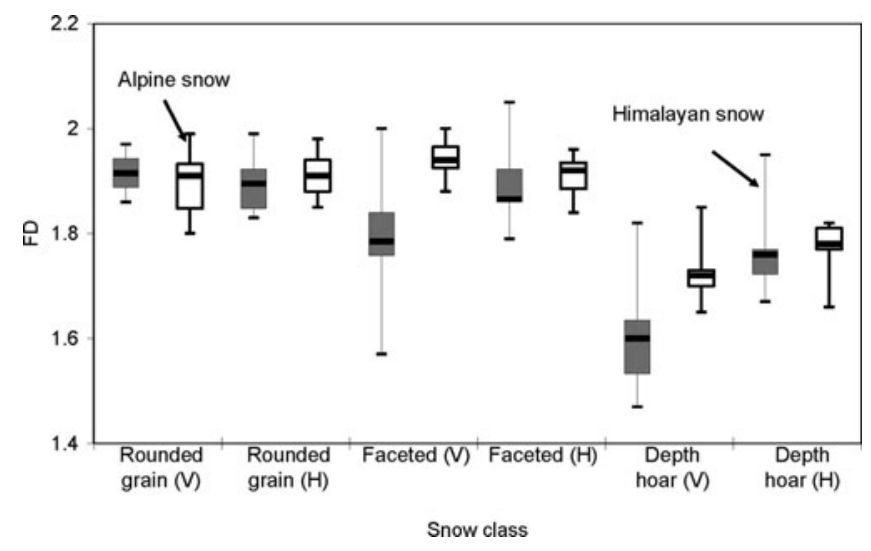

Fig. 9. Box plot of fractal dimension (FD). Himalayan snow is shown in shaded gray and alpine snow shown with white box plots. The data are from sample size of 156 as shown in Table 1. $\mathrm{H}$ and $\mathrm{V}$ represent terms similar to those in Figure 4.

The technique of geostatistics is utilized to explain the issue of randomness and continuity of spatial data by using the SV. Higher spatial continuity, observed in melt-freeze and depth-hoar signals, is characterized by smaller values of FD; less spatial continuity, observed in rounded-grain snow, is distinguished by larger FD. The results indicate that spatial scales are important parameters for characterizing snow class. The sampling resolution $(4 \mu \mathrm{m})$ seems to be sufficient to explain the small-scale variations. The method used here is found to be robust because it gives direct information from SMP profiles. The SMP data are analysed for major snow classes due to lack of other snow-class data (surface hoar, wet snow, etc.). The method demonstrated here is, however, a helpful tool in analysing snow profiles objectively. Here we have shown that SV can be used to estimate spatial scales of different snow classes. This is the first effort to use geostatistics in this direction, and further work will help to connect this information with physical and mechanical properties.

\section{REFERENCES}

Bansal, A.R. and V.P. Dimri. 2005. Self-affine gravity covariance model for the Bay of Bengal. Geophys. J. Int., 161(1), 21-30.

Birkeland, K., K. Kronholm and S. Logan. 2004. A comparison of the spatial structure of the penetration resistance of snow layers in two different snow climates. In Ganju, A., ed. Proceedings of the International Symposium on Snow Monitoring and Avalanches, 12-16 April 2004, Manali, India. Manali, Snow and Avalanche Study Establishment, 3-11.

Brun, E., P. David, M. Sudul and G. Brunot. 1992. A numerical model to simulate snow-cover stratigraphy for operational avalanche forecasting. J. Glaciol., 38(128), 13-22.

Carr, J.R. 1995. Numerical analysis for the geological sciences. Englewood Cliffs, NJ, Prentice-Hall.

Chamoli, A., A.R. Bansal and V.P. Dimri. 2007. Wavelet and rescaled range approach for the Hurst coefficient for short and long time series. Comput. Geosci., 33(1), 83-93.

Colbeck, S.C. and 7 others. 1990. The international classification for seasonal snow on the ground. Wallingford, Oxon, International Association of Scientific Hydrology. International Commission on Snow and Ice.

Cressie, N.A.C. 1993. Statistics for spatial data. New York, etc., John Wiley and Sons.

Cross, S.S. 1997. Fractals in pathology. J. Pathol., 182(1), 1-8.

Dadic, R., M. Schneebeli, M. Lehning, M.A. Hutterli and A. Ohmura. 2008. Impact of the microstructure of snow on its

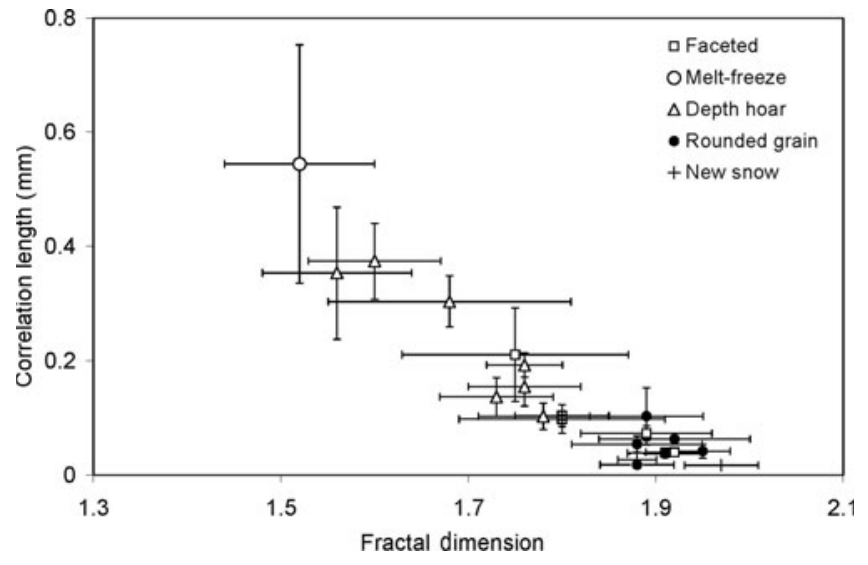

Fig. 10. Variation of $\mathrm{CL}$ with FD. Standard mean error bars are shown.

temperature: a model validation with measurements from Summit, Greenland. J. Geophys. Res., 113(D14), D14303. (10.1029/2007JD009562.)

Davis, J.C. 1986. Statistics and data analysis in geology. Second edition. New York, etc., John Wiley and Sons.

De Santis, A., M. Fedi and T. Quarta. 1997. A revisitation of the triangular prism surface area method for estimating the fractal dimension of fractal surfaces. Ann. Geof., 40(4), 811-821.

Deems, J.S., S.R. Fassnacht and K. Elder. 2006. Fractal distribution of snow depth from lindar data. J. Hydromet., 7(2), 285-297.

Dimri, V.P., ed. 2000. Application of fractals in earth sciences. New York, A.A. Balkema.

Eugster, H.P. von. 1950. Zur Morphologie und Metamorphose des Schnees. Eidg. Inst. für Schnee- Lawinenforsch. Interner Ber. 113.

Feder, J. 1988. Fractals. New York, Plenum Press.

International Association of Scientific Hydrology (IASH). Commission on Snow and Ice. 1954. The international classification for snow. Ottawa, Ont., National Research Council of Canada. Associate Committee on Soil and Snow Mechanics. (ACSSM Tech. Mem. 31.)

Jaksa, M.B., W.S. Kaggwa and P.I. Brooker. 1993. Geostatistical modelling of the spatial variation of the shear strength of a stiff, overconsolidated clay. In Li, K.S. and S.-C.R. Lo, eds. Proceedings of the Conference on Probabilistic Methods in Geotechnical Engineering, 10-12 February 1993, Canberra, Australia. Rotterdam, A.A. Balkema.

Johnson, J.B. 2003. A statistical micromechanical theory of cone penetration in granular materials. ERDC/CRREL Tech. Rep. 03-3.

Johnson, J.B. and M. Schneebeli. 1999. Characterizing the microstructural and micromechanical properties of snow. Cold Reg. Sci. Technol., 30(1-3), 91-100.

Korvin, G. 1992. Fractal models in the earth sciences. Amsterdam, etc., Elsevier.

Kronholm, K. 2004. Spatial variability of snow mechanical properties with regard to avalanche formation. (PhD thesis, University of Zürich.)

Kronholm, K., M. Schneebeli and J. Schweizer. 2004. Spatial variability of micropenetration resistance in snow layers on a small slope. Ann. Glaciol., 38, 202-208.

Lehning, M., P. Bartelt, B. Brown, C. Fierz and P. Satyawali. 2002. A physical SNOWPACK model for the Swiss avalanche warning. Part II: snow microstructure. Cold Reg. Sci. Technol., 35(3), 147-167.

Lutz, E.R. 2009. Spatial and temporal analysis of snowpack strength and stability and environmental determinants on an inclined forest opening. (PhD thesis, Montana State University.)

Lutz, E., K.W. Birkeland, K. Kronholm, K. Hansen and R. Aspinall. 2007. Surface hoar characteristics derived from a snow 
micropenetrometer using moving window statistical operations. Cold Reg. Sci. Technol., 47(1-2), 118-133.

Matzl, M. and M. Schneebeli. 2006. Measuring specific surface area of snow by near-infrared photography. J. Glaciol., 52(179), 558-564.

Mela, K. and J.N. Louie. 2001. Correlation length and fractal dimension interpretation from seismic data using variograms and power spectra. Geophysics, 66(5), 1372-1378.

Oliver, M.A. and R. Webster. 1986. Semi-variograms for modelling the spatial pattern of landform and soil properties. Earth Surf. Process. Landf., 11(5), 491-504.

Pfeiffer, D.U. 1996. Issues related to handling of spatial data. In McKenzie, J., ed. Proceedings of the Epidemiology and State Veterinary Programmes. New Zealand Veterinary Association/ Australian Veterinary Association Second Pan Pacific Veterinary Conference, 23-28 June 1996, Christchurch, New Zealand. Wellington, New Zealand Veterinary Association, 83-105.

Pielmeier, C. 2003. Textural and mechanical variability of mountain snowpacks. (PhD thesis, University of Berne.)

Pielmeier, C. and J. Schweizer. 2007. Snowpack stability information derived from the SnowMicroPen signal. Cold Reg. Sci. Technol., 47(1-2), 102-107.

Pielmeier, C., J. Schweizer and T. Stucki. 2005. Application of the SnowMicroPen to derive stability information for avalanche forecasting. In Elder, K., ed. A merging of theory and practice. Proceedings of the 2004 International Snow Science Workshop, Jackson Hole, Wyoming, 19-24 September 2004. Jackson Hole, WY, International Snow Science Workshop, 177-181.

Ribeiro, P.J., Jr, and P.J. Diggle. 2001. geoR: a package for geostatistical analysis. R-News, 1(2), 15-18.
Satyawali, P.K., M. Schneebeli, C. Pielmeier, T. Stucki and A.K. Singh. 2009. Preliminary characterization of Alpine snow using SnowMicroPen. Cold Reg. Sci. Technol., 55(3), 311-320.

Schneebeli, M., C. Pielmeier and J.B. Johnson. 1999. Measuring snow microstructure and hardness using a high resolution penetrometer. Cold Reg. Sci. Technol., 30(1-3), 101-114.

Singh, A., P.K. Satyawali, P.K. Srivastava, D.N. Sethi and A. Ganju. 2004. Snow cover modelling for Indian Himalaya. In Ganju, A., ed. Proceedings of the International Symposium on Snow Monitoring and Avalanches, 12-16 April 2004, Manali, India. Chandigarh, Snow Avalanche Study Establishment.

Turcotte, D.L. 1997. Fractals and chaos in geology and geophysics. Second edition. New York, etc., Cambridge University Press.

Van Herwijnen, A., S. Bellaire and J. Schweizer. In press. Comparison of micro-structural snowpack parameters derived from penetration resistance measurements with fracture character observations from compression tests. Cold Reg. Sci. Technol.

Wallace, J., B. Morris and P. Howarth. 2004. The effects of scale on fractal dimension of topography: a case study from Sudbury, Ontario, Canada. In IGARSS 2004. 24th International Geoscience and Remote Sensing Symposium, 20-24 September 2004, Anchorage, Alaska, USA. Proceedings, Vol. 5. Piscataway, NJ, Institute of Electrical and Electronics Engineers, 2845-2848.

Webster, R. and M.A. Oliver. 2001. Geostatistics for environmental scientists. Chichester, John Wiley and Sons.

Zhang, Y., M. Person, C. Paola, C.W. Gable, X.-H. Wen and J.M. Davis. 2005. Geostatistical analysis of an experimental stratigraphy. Water Resour. Res., 41(W11), W11416. (10.1029/ 2004WR003756.) 